\title{
BMJ Open Trends in inequality in life expectancy at birth between 2004 and 2017 and projections for 2030 in Korea: multiyear cross-sectional differences by income from national health insurance data
}

To cite: Khang Y-H, Bahk J, Lim D, et al. Trends in inequality in life expectancy at birth between 2004 and 2017 and projections for 2030 in Korea: multiyear cross-sectional differences by income from national health insurance data. BMJ Open 2019;9:e030683. doi:10.1136/ bmjopen-2019-030683

- Prepublication history and additional material for this paper are available online. To view these files, please visit the journal online (http://dx.doi org/10.1136/bmjopen-2019030683).

Received 26 March 2019 Revised 10 June 2019 Accepted 12 June 2019

Check for updates

(C) Author(s) (or their employer(s)) 2019. Re-use permitted under CC BY-NC. No commercial re-use. See rights and permissions. Published by BMJ.

For numbered affiliations see end of article.

Correspondence to Young-Ho Khang; yhkhang@snu.ac.kr

\section{ABSTRACT}

Objectives The current status, time trends and future projections of a national health equity target are crucial elements of national health equity surveillance. This study examined time trends in inequality by income in life expectancy (LE) at birth between 2004 and 2017 and made future projections for the year 2030 in Korea. Design Using individually linked mortality data, time trends in inequality by income in LE at birth were examined. The LE projection was made with the LeeCarter model.

Setting Total Korean population and death data derived from the National Health Information Database of the National Health Insurance Service.

Participants A total of 685773157 subjects and 3486 893 deaths between 2004 and 2017 were analysed.

Primary and secondary outcome measures Annual LE and the magnitude of inequality by income in LE between 2004 and 2030.

Results Inequality by income in LE among the total Korean population increased during the past 14 years, and this inequality is projected to become even greater in the future. In 2030, the magnitude of inequality by income in LE is projected to increase by 0.25 years in comparison to the magnitude in 2017. The increase in LE inequality was projected to be more prominent among women, with a projected 1.08 year increase in LE inequality between 2017 and 2030.

Conclusion Aggressive policies should be developed to close the increasing LE gap in Korea. LE inequalities by income should be considered as a measurable target for health equity in the process of establishing the National Health Plan 2030 in Korea.

\section{INTRODUCTION}

The Commission on Social Determinants of Health (CSDH) set up by the WHO presented, as one of its three overarching recommendations, the message that health inequality measurement is a vital platform for action. ${ }^{1}$ The CSDH recommended that national governments establish a national
Strengths and limitations of this study

- Prior studies have provided evidence on inequalities by income in life expectancy (LE) but were based on sampled data or self-reported information on household income which was missing for substantial proportion of the total population.

- Prior studies presented inequalities in LE at certain ages in adulthood while this study presented inequalities in LE at birth.

- This study simultaneously presented time trends in LE inequalities by income and their future projections.

- The income proxy has been used based on national health insurance premium, which might have resulted in attenuated magnitude of inequalities in LE.

- The current study could not present time trends in LE inequalities before 2004 because the data before 2004 were not available.

health equity surveillance system, with routine collection of data on social determinants of health and health inequities (recommendation 16.3). ${ }^{1}$ The current status, time trends and future projections of a national health equity target are crucial elements of national health equity surveillance. For example, the UK government established national targets for health equity for the year 2010 based on time trends in life expectancy (LE) and infant mortality and their projections. ${ }^{2}$

South Korea (hereafter 'Korea') has a tradition of adopting differences between income quintiles in health indicators as health equity targets. In the revised Health Plan 2010 established by the Ministry of Health and Welfare, differences between income quintiles in all-cause mortality and two health behaviours (cigarette smoking and physical activity) were set as measurable health equity 
targets for the year 2010. ${ }^{3}$ Recently, LE by income quintiles based on the National Health Information Database (NHID) of the National Health Insurance Service (NHIS) has been suggested as a national health equity target for the upcoming National Health Plan 2030. ${ }^{4}$ Socioeconomic inequalities in LE rather than socioeconomic inequalities in mortality or health behaviours might be better accepted as the overarching target for health equity to the public. A recent study showed that both relative and absolute educational inequality in mortality had not decreased in the four decades since 1970 in Korea. ${ }^{5}$ Each socioeconomic position (SEP) indicator has distinct influences in promoting or damaging population health. ${ }^{6}$ Education may reflect early life socioeconomic situations ${ }^{7}$ while income delivers information on material advantages or disadvantages. ${ }^{6}$ LE by income than other SEP indicators might be better in monitoring the impact of concurrent economic and social policies related to material conditions on the magnitude of health inequality. Prior Korean studies explored cross-sectional inequalities in LE by income and suggested that LE inequalities by income calculated using the NHID should be an important measure for health equity monitoring in Korea. ${ }^{8-10}$ Several studies from Western countries, including Canada, ${ }^{11}$ Denmark, ${ }^{12}$ Finland,${ }^{13-15}$ New Zealand $^{1617}$ and the USA, ${ }^{18}$ have examined LE inequalities by income. Chetty and colleagues examined the relationship between income and LE in the USA and demonstrated that the health inequalities between top and bottom income groups had widened between 2001 and 2014. ${ }^{18}$ No Korean studies have presented time trends of income-based inequality (inequality according to income groups) in LE or made projections of incomebased inequality in LE in the future. An analysis of time trends in income-based inequality in LE and future projections thereof could lead to significant progress in establishing a national overarching target for health equity in Korea. This study was conducted to explore time trends of income-based inequality in LE in Korea and to make future projections for the year 2030.

\section{METHODS \\ Data}

We used population and death data from the NHID of the NHIS individually linked to mortality registration data of Statistics Korea between 2004 and 2017. ${ }^{19}$ Data for the years before 2004 were not available in the NHID. The data cover all national health insurance (NHI) beneficiaries in Korea, except for soldiers, their dependents and foreigners. A recent Korean study indicated that the NHID data for the numbers of population and death and associated LE values were representative of the entire Korean population and constituted a good source for monitoring mortality and $\mathrm{LE}^{20}{ }^{20}$ Individual data linkage was conducted internally in the NHIS with assistance of Statistics Korea. Aggregate population and death data without personal identification numbers according to sex, age $(0,1-4,5-9,10-14, \ldots, 80-84$ and $85+)$, and income quintiles were obtained from the Big Data Steering Department of the NHIS. Online supplementary table 1 presents the annual numbers of population and death by sex and income quintiles between 2004 and 2017. During the study period, a total of 685773157 subjects (342 731537 women and 343041620 men) and 3486893 deaths (1 579781 women and 1907112 men) were analysed.

\section{SEP indicator}

We used income as the SEP indicator in this study. Income information was based on the NHI premiums. Several prior Korean studies have used this premium as a proxy for income. ${ }^{8-10}$ Administratively collected data from the National Tax Service of Korea were used for determining the NHI premiums. The NHI premiums for the employed were proportionally levied on the average monthly salaries over the previous calendar year. The NHI premium for the self-employed were levied based on the estimated income using information on sex, age, recorded income, property and vehicles ownership. Individuals in the Medical Aid Programme (approximately $3 \%$ of the total Korean population) are exempt from NHI premiums. Any major changes on the NHI premium levy system have not been made between 2004 and 2017. The NHI premiums were computed on 1 January each year for the entire Korean population and then applied to all age groups because dependents of the employed NHI beneficiary shared the same premiums. The premiums were finally grouped into quintiles based on the population size. Prior studies found similar patterns in LE inequalities when separately analysed the data for those not self-employed and those self-employed. ${ }^{9}{ }^{10}$ The NHI premium also has policy relevance since nearly 30 governmental healthcare and social welfare programmes (eg, the Nutrition Plus programme, community child care centre services, medical expenditure subsidy programmes, social support programmes for disabled people, national cancer screening, and home visit and social support programmes for the elderly) utilise the NHI premium to select beneficiaries. We employed age group-specific equivalised income, taking into account the household size, and categorised the equivalised income into quintiles at the nearest quintile points. Since no premium was levied for Medical Aid programme beneficiaries (about 3\% of the total population), these beneficiaries were grouped into the lowest income quintile.

\section{Statistical analysis}

Using annual numbers of population and deaths by sex, age groups and income quintiles, we constructed life tables using the 5-year probabilities of death according to income quintiles for the years between 2004 and 2017. We employed the Kannisto-Thatcher method to expand the open-ended age interval $85+$ to estimate the probability of dying for the 5-year age groups of 85-89, 90-94, ..., 120-124 and $125+{ }^{21}$ To obtain LE projections for the 
future, the Lee-Carter model, which is frequently used in forecasting mortality and LE, was utilised..$^{22-24}$ The Lee-Carter model uses a matrix of age-specific mortality rates ordered by years in a country. Using a forecasted matrix of age-specific mortality rates, LE in the upcoming years was estimated. We also estimated prediction intervals of LE at birth between 2018 and 2030 based on the prediction intervals for mortality by year, sex, age groups and income quintiles. In this study, we used the difference between income quintiles and the slope index of inequality as measures of inequality in LE. Based on the calculated LE by income quintile, we estimated the slope index of inequality. To calculate the slope index of inequality, we employed a relative income distribution indicator (a value between 0 and 1), reflecting the relative position in the cumulative population distribution of the central subject in the income hierarchy. The relative position indicator was used as an independent variable in the linear regression analysis for the slope index of inequality. The slope index of inequality in LE refers to the absolute difference between LE at the lowest end of the income distribution and LE at the very top of the income distribution. ${ }^{25}$

\section{Patient and public involvement}

No patients were involved in the development and design of this study.

\section{RESULTS}

Online supplementary table 1 presents the numbers of population and deaths by income quintiles between 2004 and 2017. Since the income quintiles were grouped at age group-specific income quintile points, the numbers of deaths in the lower income quintiles compared with the numbers of deaths in the highest income quintile reflect the excess deaths associated with low income, taking into account the age distribution of income groups. During the 14 years between 2004 and 2017, a total of 843918 excess deaths (265471 deaths in women and 578557 deaths in men) were attributable to low income, using the highest income quintile as the reference group. The excess deaths (144177 deaths in women and 301647 deaths in men) in the lowest income quintile group accounted for $52.8 \%$ of the total excess deaths $(=(445824 / 843918) * 100)$. In addition, the total excess deaths due to low income $(n=843918)$ were about 3.4 times the average annual number of deaths during the study period $(\mathrm{n}=249064)$.

Figure 1 and online supplementary tables 2 and 3 present annual LEs by sex between 2004 and 2017 and a projection of LE (with prediction intervals) by sex through 2030. Over the 14-year period between 2004 and 2017, the total Korean population recorded an LE increase of 5.01 years (4.56 years for women and 5.36 years for men). It was projected that in 2030, LE among Korean women would reach 89.84 years. The mean LE in 2017 was 86.04 for women and 80.01 for men (a 6.03-year difference by sex). The difference in LE by sex decreased during the study period (6.83 years in 2004 and 6.03 years in 2017) (see online supplementary figure 1). Figure 1 and online supplementary table 3 and figure 1 also show that the sex-based difference in LE is projected to decrease further to 5.51 years in 2030 .

Figure 2 and online supplementary table 2 show that, despite the increases in all income groups, the LE in the lowest income quintile in 2017 (79.32 years in men and women combined) was lower than the LE in the highest income quintile in 2004 (80.97 years in men and women combined). This pattern held true for men. However, the LE among women in the lowest income quintile in 2017 (83.38 years) was slightly greater than the LE among women in the highest income quintile in 2004 (83.05 years) (figure 3 and online supplementary table 2).

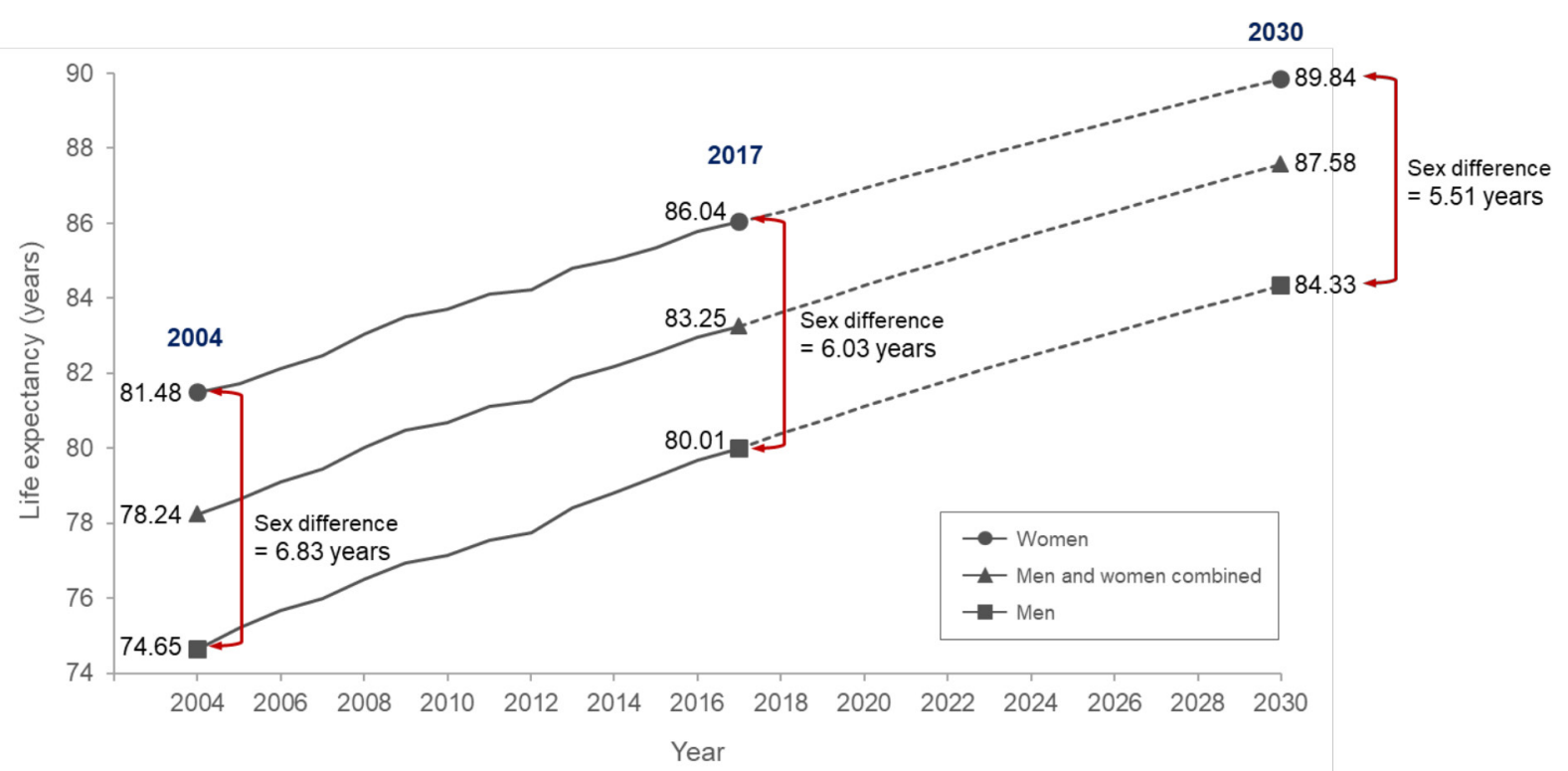

Figure 1 Trends in life expectancy by sex in Korea between 2004 and 2017 and projections to 2030. 


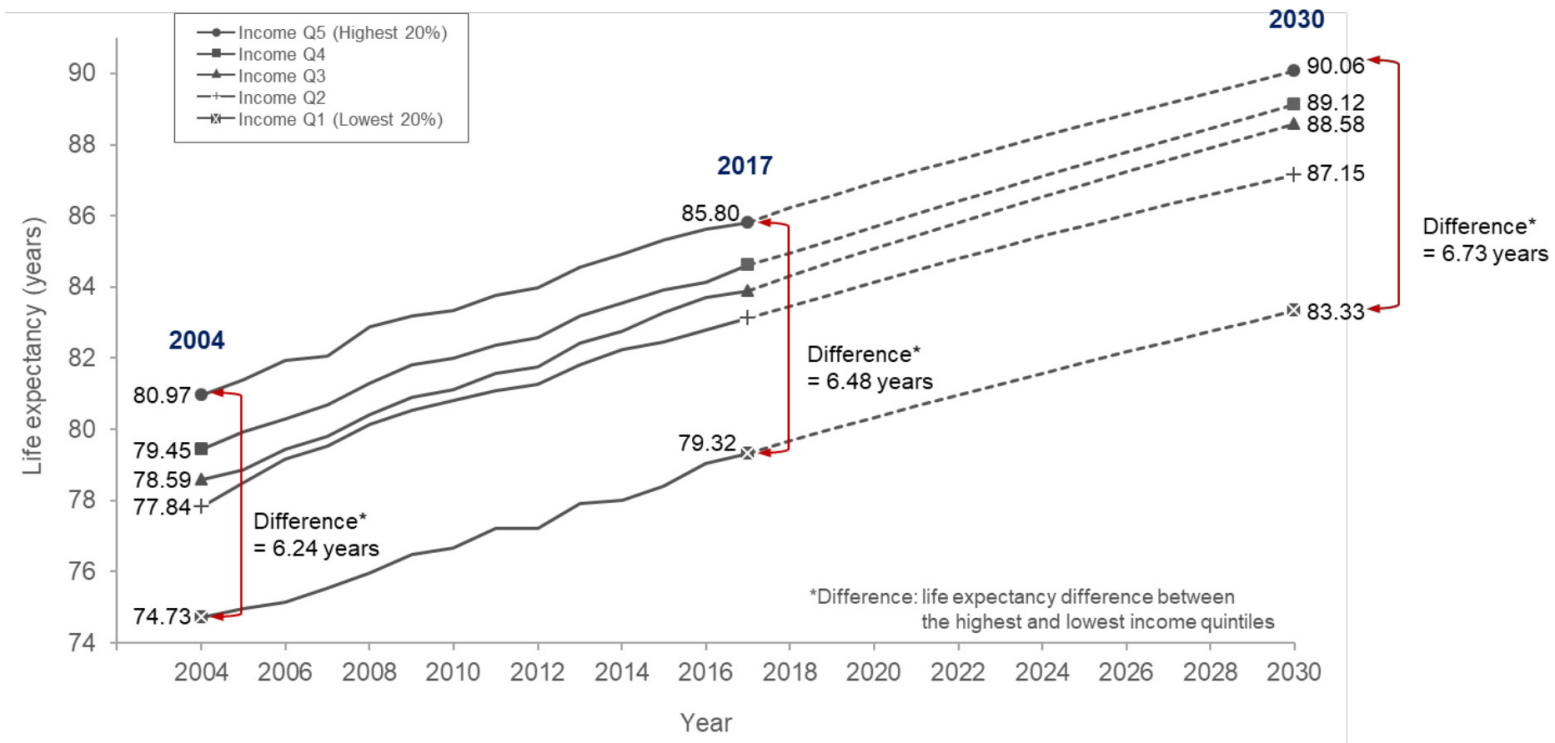

Figure 2 Trends in life expectancy by income among Korean women and men combined between 2004 and 2017 and projections to 2030 .

Figures 2 and 3, online supplementary table 2 and figure 2, also show trends in LE inequality by income between 2004 and 2017. In 2017, the LE differences between the highest and lowest income quintiles were 6.48 years for women and men combined, 4.34 years for women and 7.91 years for men. The slope index of inequality in LE showed greater differences in all years among women and men. The magnitude of inequality in LE, as measured by differences between income quintiles and the slope index of inequality, increased over time. The LE difference among total population increased by 0.24 years (from 6.24 in 2004 to 6.48 in 2017). This increase was prominent among women: from 3.69 years in 2004 to 4.34 years in 2017 (an 0.65 year increase). In men, a stable and even decreasing trend in LE inequality was noticed both for the difference between income quintiles and for the slope index of inequality.

Figures 2 and 3 and online supplementary table 3 present future projections of LE by income quintile to the year 2030 based on the Lee-Carter model. It was projected that LE would increase steadily in all income groups in both women and men. The LE gains in high-income women would be greater than the gains in low-income women. As the result, in 2030, the LE among men in the highest income quintile (86.94 years) would surpass the LE among women in the lowest income quintile (86.55 years). Figures 2 and 3, online supplementary table 3 and figure 2, also show future projections for income-based inequality in LE. In 2030, the LE difference between the highest and lowest income quintiles was projected to become larger: a 6.73-year difference among women and men combined, a 5.42-year difference among women and a 7.21-year difference among men. The slope index of inequality was likewise projected to indicate greater magnitudes of inequality in LE in the future.
Figure 3 and online supplementary table 2 indicate that the difference in LE by sex in the lowest income quintile was the greatest (an 8.07-year difference in 2017) among the five income groups, while the sex gap was smallest in the highest income quintile (4.50-year difference in 2017). However, because of the greater improvement in $\mathrm{LE}$ in the lowest income quintile of Korean men through 2030, the sex gap in LE inequality among income quintiles was projected to decrease (6.82 years in 2030 in the lowest income quintile and 5.03 years in 2030 in the highest income quintile).

\section{DISCUSSION}

The results of this study indicated that income-based inequality in LE among the total Korean population increased during the past 14 years, and this inequality is projected to become even greater, especially among women, in the future. By 2030, the magnitude of inequality by income in LE was projected to increase by 0.25 years. The increase in LE inequality was projected to be especially prominent among women, with a 1.08-year increase in LE inequality between 2017 and 2030. This finding constitutes an urgent alert to the Korean government and suggests that income-based inequalities in LE should be included as a quantifiable health equity target in the National Health Plan 2030. ${ }^{4}$

Several previous studies examined socioeconomic inequality in mortality and LE over the past decades in Korea and found an unabated trend towards inequality. ${ }^{5} 2627$ The increase in LE inequality according to education was clearer in women than in men. ${ }^{27}$ The Asian economic crisis in the late 1990s, the global economic crisis in 2008 and associated structural adjustments in the Korean economic and social infrastructure might have contributed to the increase in inequality in 

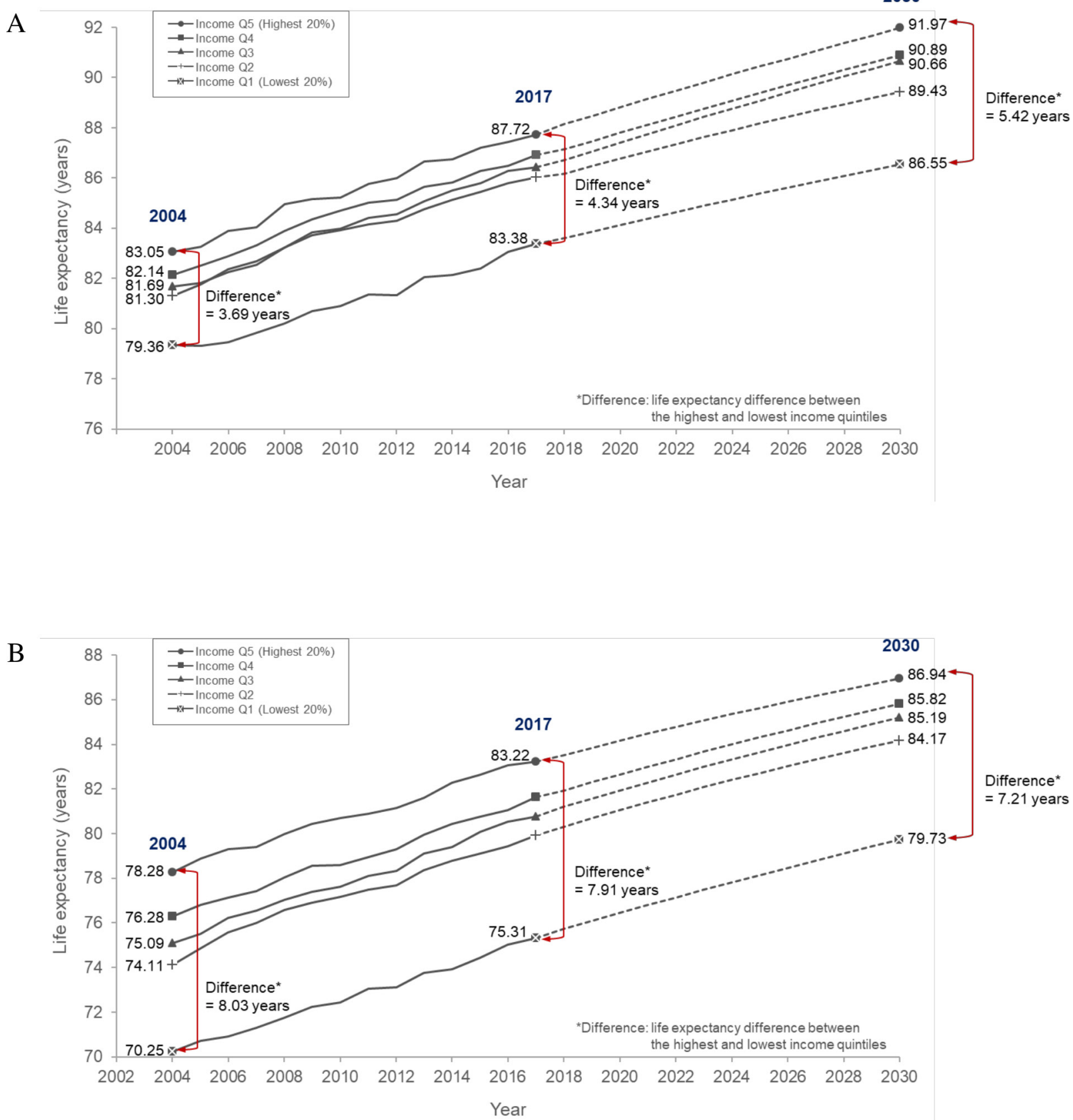

Figure 3 Trends in life expectancy by income in (A) women and (B) men in Korea and projections to 2030.

LE. It was suggested that Korean women have been victimised by these economic crises, as Korean women (especially middle-age women) were most severely exposed to labour market flexibility, leading to job insecurity and downward social mobility. ${ }^{27}$ Understanding age-specific and cause-specific contributions to inequality trends would be helpful for deciphering the impact of these determinants. Changes in socioeconomic inequality in health behaviours should also be considered to explain these trends. For example, prior studies conducted in Korea showed that socioeconomic inequality in cigarette smoking increased since the late 1990s in both men and women, but the absolute smoking rate in Korean women did not decrease, in contrast to the rate in Korean men. ${ }^{2829}$
Time trends in income-based inequality in LE can be reflected in terms of time trends in income inequality. As shown in online supplementary figure 3 , Hong presented that Korea has recorded substantial increases in income inequality measured by income share $(\%)$ of the top $10 \%$ income group between 1958 and $2013 .{ }^{30}$ Statistics Korea also showed the increase in income inequality measured by Gini coefficient and the ratio of the average income of the $20 \%$ richest to the $20 \%$ poorest (online supplementary figures 4 and 5). Three different explanations have been suggested to link income inequality to population health (absolute income effect, relative income effect and contextual pollution effect of income inequality). ${ }^{31}$ The relative importance of the mechanisms 
(psychosocial perspectives vs neomaterial perspectives) has been debated ${ }^{32-34}$ Prior studies showed that decrease in income inequality was associated with decreases in overall mortality and, to a larger degree, decreases in socioeconomic inequality in mortality. ${ }^{35} 36$ The continually increasing income inequalities in Korea might have had both acute and lagged effects on widened LE differences by income quintile presented in this study.

Several Western studies have provided evidence on LE inequalities by income. However, several studies from Canada ${ }^{11}$ and Finland ${ }^{13-15}$ were based on sampled data. The studies from New Zealand were based on self-reported information on household income, which was missing for $16 \%-20 \%$ of the respondents. ${ }^{16}{ }^{17}$ Furthermore, all these Western studies presented inequalities in LE at certain ages in adulthood, rather than inequalities in LE at birth, as presented in this study. Inequalities in LE at birth present overall inequalities in mean length of life capturing inequalities in mortality during infancy and childhood periods as well as adulthood and elderly periods. Inequalities in health during early life could have lifetime impacts. It should be also noted that income inequality was especially associated with increased infant mortality. ${ }^{37}$ No prior studies have simultaneously presented time trends in LE inequalities and their future projections, as was done in this study. Nonetheless, many of the Western studies showed increasing LE inequality by income. ${ }^{12-18}$ Meanwhile, studies from Denmark $^{12}$ and New Zealand ${ }^{16}{ }^{17}$ showed increasing LE inequalities in men but decreasing or stagnant inequalities in women, which contrasts with the results of this study regarding sex-specific patterns in the time trends of LE inequalities. The difference between findings from these Western countries and results of this study may be partly attributable to the relative importance of causes of death contributing to total mortality and their time trends in men and women. A prior New Zealand study showed that, while cardiovascular disease becomes a less common cause of death and its contribution to overall income inequalities in total mortality declined, cancers especially associated with smoking have been emerged as the major driver of inequalities in mortality. ${ }^{38}$ In Korea where smoking epidemic and westernisation of diet has been delayed, lung cancer and ischaemic heart disease, which are major causes of death in Western countries, have been relatively recently emerged as one of leading causes of death in Korea. ${ }^{39}$ Meanwhile, stroke (especially haemorrhagic stroke), stomach cancer, liver cancer, liver cirrhosis and tuberculosis have substantially decreased and have contributed to rapid increase in LE especially among men. ${ }^{39}$ Unabated declines in these causes of death might have provided a continuous momentum to decrease inequalities in LE in Korean men. Future studies examining the contribution of specific causes of death to the changes in LE inequalities in men and women might provide better explanations regarding the gender difference in time trends in LE inequalities between Western countries and Korea.
This study showed that the difference in LE between the lowest income quintile group and the second-lowest income quintile group was greater in both women and men than any other differences in neighbouring income quintiles. About half $(52.8 \%)$ of the total excess deaths due to lower income compared with the highest income quintile came from the lowest income quintile. The reason for the disadvantage in LE among the lowest income quintile group might be that the lowest income quintile included recipients of Medical Aid and low-income self-employed individuals in Korea. ${ }^{9}{ }^{10}$ Figure 2 shows that, in 2030, the top three income quintiles in women were projected to record an LE over 90. A prior LE projection study indicated that Korean women would have the highest LE in the world by 2030 , with a $57 \%$ probability of them having an LE greater than 90 years. ${ }^{40}$ The results of this study suggest that, without an increase in LE inequality, the prior projection for the 2030 LE in Korean women would be more easily realised.

The difference in LE by sex decreased from 2004 (6.83 years) to 2017 (6.03 years) and was projected to decrease further by 2030 (5.51 years). This decrease was largely due to a shrinking gap in LE by sex in the lower income quintiles between 2004 and 2017 (from 9.11 years to 8.07 years in the lowest income quintile and from 7.19 years to 6.12 years in the second-lowest income quintile). A prior Korean study explored differences in LE by sex between 1970 and 2005 and indicated that liver disease, hypertension-related diseases and transport accidents were causes of death that made major contributions to the reduction of differences in LE by sex. ${ }^{41}$ These causes of deaths showed long-term decreasing trends in cause-specific mortality data, ${ }^{42}$ thereby contributing to the increase in LE, especially among Korean men. ${ }^{39}$ Furthermore, that prior study also revealed that smoking-related causes of death (lung cancer and lower respiratory disease) contributed to increasing the difference in LE by sex. ${ }^{41}$ The sustained prevalence of cigarette smoking among Korean women likely contributes to a decreasing difference in LE by sex, as well as increasing inequalities in LE among women.

This study has limitations. The income variable in this study was based on NHI premium. Use of this income proxy might have resulted in attenuated magnitude of inequalities in LE. However, this might have not affected time trends in inequalities in LE since the same income variable was used over the study period. This study could not present time trends in LE inequalities before 2004 because the data before 2004 were not available from NHID.

In conclusion, this study showed that LE inequalities by income increased in the past 14 years and are projected to widen further by the year 2030. Considering that Korea has a tradition employing differences between income quintiles in health status as health equity targets and LE is a summary measure for total mortality over the life course, inequalities in LE at birth by income should be considered as a measurable target for health equity in the 
process of establishing the National Health Plan 2030 in Korea. In addition, aggressive policies should be developed to close the increasing LE gap in Korea.

\section{Author affiliations}

${ }^{1}$ Department of Health Policy and Management, Seoul National University College of Medicine, Seoul, Republic of Korea

${ }^{2}$ Institute of Health Policy and Management, Seoul National University Medical Research Center, Seoul, Republic of Korea

${ }^{3}$ Department of Public Health, Keimyung University, Daegu, Republic of Korea ${ }^{4}$ Big Data Steering Department, National Health Insurance Service, Wonju, Republic of Korea

Contributors $\mathrm{Y}$-HK conceived the study idea, supervised the analysis and drafted the manuscript. JB, DL and $\mathrm{H}-\mathrm{KL}$ conducted the analysis. $\mathrm{H}-\mathrm{YK}$ obtained the data. $Y$ YYK and JHP contributed to the data curation. All authors discussed the results and contributed to the final manuscript.

Funding This work was supported by a grant of the Korea Health Technology R\&D Project through the Korea Health Industry Development Institute (KHIDI), funded by the Ministry of Health and Welfare, Republic of Korea (grant number: HI18C0446). Y-HK was also supported by a grant from Seoul National University Hospital.

Competing interests None declared.

Patient consent for publication Not required.

Ethics approval The study was approved by the National Health Insurance Service of Korea and the Seoul National University Hospital Institutional Review Board (IRB No. E-1605-006-758)

Provenance and peer review Not commissioned; externally peer reviewed.

Data sharing statement Individual data linkage of population and mortality data was made internally in the Big Data Steering Department of the National Health Insurance Service. The authors used aggregate population and death data without personal identification numbers. Deidentified aggregate data can be requested from Y-HK after permissions are obtained from the Big Data Steering Department of the National Health Insurance Service in Korea.

Open access This is an open access article distributed in accordance with the Creative Commons Attribution Non Commercial (CC BY-NC 4.0) license, which permits others to distribute, remix, adapt, build upon this work non-commercially, and license their derivative works on different terms, provided the original work is properly cited, appropriate credit is given, any changes made indicated, and the use is non-commercial. See: http://creativecommons.org/licenses/by-nc/4.0/.

\section{REFERENCES}

1. Commission on Social Determinants of Health. Closing the gap in a generation: health equity through action on the social determinants of health. Final report of the commission on social determinants of health. Geneva: World Health Organization, 2008.

2. UK Department of Health. Health inequalities - national targets on infant mortality and life expectancy - technical briefing. https:// webarchive.nationalarchives.gov.uk/20040105031524/http://www. doh.gov.uk:80/healthinequalities/publications.htm (Accessed 4 Dec 2018).

3. Khang YH, Lee SI. Health inequalities policy in Korea: current status and future challenges. J Korean Med Sci 2012;27 Suppl:S33-40.

4. Korean Society for Equity in Health, Ministry of Health and Welfare of Korea. Developing key indicators of health equity and strategies for reducing health disparity in national health plan. Sejong, Korea: Korean Society for Equity in Health and Ministry of Health and Welfare of Korea, 2016.

5. Bahk J, Lynch JW, Khang YH. Forty years of economic growth and plummeting mortality: the mortality experience of the poorly educated in South Korea. J Epidemiol Community Health 2017;71:282-8.

6. Lynch J, Kaplan G. Socioeconomic position. In: Berkman LF, Kawachi I, eds. Social epidemiology. New York: Oxford University Press, 2000:13-35.

7. Davey Smith G, Hart C, Hole D, et al. Education and occupational social class: which is the more important indicator of mortality risk? J Epidemiol Community Health 1998;52:153-60.

8. Khang YH, Yang S, Cho HJ, et al. Decomposition of socio-economic differences in life expectancy at birth by age and cause of death among 4 million South Korean public servants and their dependents. Int J Epidemiol 2010;39:1656-66.

9. Khang YH, Bahk J, Yi N, et al. Age- and cause-specific contributions to income difference in life expectancy at birth: findings from nationally representative data on one million South Koreans. Eur J Public Health 2016;26:242-8.

10. Khang $\mathrm{YH}$, Yoon SC, Yi N. Patterns of income differences in life expectancy and age- and cause-specific contributions to the differences: findings from mortality follow-up data of nationally representative one million Koreans: National Health Service of Korea, 2013.

11. Mclntosh $\mathrm{CN}$, Finès $\mathrm{P}$, Wilkins $\mathrm{R}$, et al. Income disparities in healthadjusted life expectancy for Canadian adults, 1991 to 2001. Health Rep 2009;20:55-64.

12. Brønnum-Hansen $H$, Baadsgaard M. Widening social inequality in life expectancy in Denmark. A register-based study on social composition and mortality trends for the Danish population. BMC Public Health 2012;12:994.

13. Tarkiainen $L$, Martikainen $P$, Laaksonen $M$, et al. Trends in life expectancy by income from 1988 to 2007: decomposition by age and cause of death. J Epidemiol Community Health 2012;66:573-8.

14. Manderbacka K, Peltonen R, Lumme S, et al. The contribution of health policy and care to income differences in life expectancy--a register based cohort study. BMC Public Health 2013;13:812.

15. Martikainen $P$, Mäkelä $P$, Peltonen $R$, et al. Income differences in life expectancy: the changing contribution of harmful consumption of alcohol and smoking. Epidemiology 2014;25:182-90.

16. Blakely T, Fawcett J, Atkinson J, et al. Decades of disparity II: socioeconomic mortality trends in New Zealand, 1981-1999. Wellington: Ministry of Health and University of Otago, 2005.

17. Carter KN, Blakely T, Soeberg M. Trends in survival and life expectancy by ethnicity, income and smoking in New Zealand: 1980s to 2000s. N Z Med J 2010;123:13-24.

18. Chetty R, Stepner M, Abraham S, et al. The association between income and life expectancy in the United States, 2001-2014. JAMA 2016;315:1750-66.

19. Cheol Seong S, Kim YY, Khang YH, et al. Data resource profile: the national health information database of the national health insurance service in South Korea. Int $J$ Epidemiol 2017;46:799-800

20. Bahk J, Kim YY, Kang HY, et al. Using the national health information database of the national health insurance service in korea for monitoring mortality and life expectancy at national and local levels. J Korean Med Sci 2017;32:1764-70.

21. Thatcher AR, Kannisto VI VJW. The force of mortality at ages 80 to 120. Odense, Denmark: Odense University Press, 1998.

22. Lee RD, Carter LR. Modeling and forecasting US mortality. J Am Stat Assoc 1992;87:659-71.

23. Booth $\mathrm{H}$, Tickle L, Smith L. Evaluation of the variants of the LeeCarter method of forecasting mortality: a multicountry comparison. New Zealand Population Review 2005;31:13-37.

24. Li N, Lee R. Coherent mortality forecasts for a group of populations: an extension of the Lee-Carter method. Demography 2005;42:575-94.

25. Harper S, Lynch J. Health inequalities: measurement and decomposition. In: Oakes JM, Kaufman JS, eds. Methods in Social Epidemiology. Second Edition. San Francisco, CA: Jossey-Bass \& Pfeiffer Imprint, Wiley, 2017:91-131.

26. Khang YH, Lynch JW, Yun S, et al. Trends in socioeconomic health inequalities in Korea: use of mortality and morbidity measures. $J$ Epidemiol Community Health 2004;58:308-14.

27. Son $\mathrm{M}, \mathrm{Cho} \mathrm{Y}, \mathrm{Oh} \mathrm{J}$, et al. Social inequalities in life expectancy and mortality during the transition period of economic crisis (1993-2010) in Korea. Int J Equity Health 2012;11:71.

28. Khang $\mathrm{YH}$, Yun SC, Cho HJ, et al. The impact of governmental antismoking policy on socioeconomic disparities in cigarette smoking in South Korea. Nicotine Tob Res 2009;11:262-9.

29. Di Cesare M, Khang $\mathrm{YH}$, Asaria $\mathrm{P}$, et al. Inequalities in noncommunicable diseases and effective responses. Lancet 2013;381:585-97.

30. Hong M. Top incomes in Korea (1958-2013). J Korean Econ Development 2015;21:1-34.

31. Kawachi I, Subramanian SV. Income inequality. In: Berkman LF, Kawachi I, Glymour MM, eds. Social Epidemiology. Second Edition. New York: Oxford University Press, 2014:126-52.

32. Hill TD, Jorgenson A. Bring out your dead!: a study of income inequality and life expectancy in the United States, 2000-2010. Health Place 2018;49:1-6.

33. Lynch J, Smith GD, Harper S, et al. Is income inequality a determinant of population health? Part 1. A systematic review. Milbank Q 2004;82:5-99. 
34. Wilkinson RG, Pickett KE. Income inequality and population health: a review and explanation of the evidence. Soc Sci Med 2006;62:1768-84.

35. Blakely T, Wilson N. Shifting dollars, saving lives: what might happen to mortality rates, and socio-economic inequalities in mortality rates, if income was redistributed? Soc Sci Med 2006;62:2024-34.

36. Brodish PH, Hakes JK. Quantifying the individual-level association between income and mortality risk in the United States using the National Longitudinal Mortality Study. Soc Sci Med 2016;170:180-7.

37. Lynch J, Smith GD, Hillemeier M, et al. Income inequality, the psychosocial environment, and health: comparisons of wealthy nations. Lancet 2001;358:194-200.
38. Fawcett $\mathrm{J}$, Blakely $\mathrm{T}$. Cancer is overtaking cardiovascular disease as the main driver of socioeconomic inequalities in mortality: New Zealand (1981-99). J Epidemiol Community Health 2007;61:59-66.

39. Yang S, Khang YH, Harper S, et al. Understanding the rapid increase in life expectancy in South Korea. Am J Public Health 2010;100:896-903.

40. Kontis V, Bennett JE, Mathers CD, et al. Future life expectancy in 35 industrialised countries: projections with a Bayesian model ensemble. Lancet 2017;389:1323-35.

41. Yang $\mathrm{S}$, Khang $\mathrm{YH}$, Chun $\mathrm{H}$, et al. The changing gender differences in life expectancy in Korea 1970-2005. Soc Sci Med 2012;75:1280-7.

42. Khang YH, Lynch JW, Kaplan GA. Impact of economic crisis on cause-specific mortality in South Korea. Int J Epidemiol 2005;34:1291-301. 